The paper was originally published as:

The Retirement of the Migrant Labor Force: Pension Portability and Beyond Alain J ousten

CESifo Economic Studies 2014;

doi: $10.1093 /$ cesifo/ifu002 


\title{
The retirement of the migrant labor force: pension portability and beyond
}

\author{
Alain Jousten \\ Université de Liège - CREPP and Tax Institute \\ Institute for the Study of Labor (IZA) \\ Network for Studies on Pensions, Aging and Retirement (Netspar)
}

$02 / 11 / 2013$

Keywords: Pensions, retirement, international migration, social security coordination

JEL Codes: F22, H75, J26, J61

\begin{abstract}
The specificities of the workforce with a migrant background are often neglected in studies of retirement. Similarly, many studies of migration's impact on pensions often focus on aggregate outcomes - system sustainability or distributive characteristics. The present paper provides a fresh look at the nexus between these two literatures. It discusses the impact of the European social security coordination mechanisms on individual decision-making and on the functioning of social security systems - with a focus on retirement. The paper argues that such effects are non-negligible and are likely to have major policy consequences.
\end{abstract}




\section{Introduction}

International migration flows have substantially increased over the last decades. In its recent International Migration Outlook (OECD, 2013) the OECD presented some compelling statistics on international migration. The foreign-born population represented on average $12.5 \%$ of the total population in OECD countries in 2011. Furthermore, immigrants accounted for $40 \%$ of total population growth in the OECD countries during the period of 2001-2011.

In this context, the European example is of particular interest. First, Europe has a longstanding history of immigration and emigration flows across borders - which means that a substantial fraction of European Union (EU) residents and citizens live in another country than their home country. Second, intra-European mobility is characterized by a rather unique right to free movement of labor that is applicable within the European Economic Area (EEA), which includes the EU. This right plays a crucial role in migration flows in the EU. For example, it accounts for approximately two thirds of immigrants to Austria and Germany according to OECD (2013).

The economic literature has long recognized the effects of migration, particularly on the destination country. One focus has been the impact on the labor market of the destination country. Kahanec (2013) provides an up-to-date review and documents no major effect of the EU enlargements on destination country labor markets - in sharp contrast to widely held fears and beliefs to the contrary among politicians and citizens alike. A second strand of the literature takes a broader macroeconomic perspective by evaluating aggregate costs and benefits for the destination country. At a conceptual level, Borjas (1995) defines the "immigration surplus" as the aggregate net gain in national income to the receiving country under the form of sustained economic activity and growth net of any losses suffered by the native population as a result of the migration. In an empirical study of the costs and benefits of migration from Central and Eastern European New Member States to the United Kingdom, Dustman et al (2010) find that the net government balance is positively affected. However, De Giorgi and Pellizzari (2009) warrant that welfare shopping - though 
not a predominant driver of migration in Europe - may nonetheless negatively affect the overall balance of migration to the receiving country.

Regarding the impact on origin countries, two topics stand out in the literature - "brain drain" and remittances. "Brain drain" occurs when relatively more skilled individuals leave a country, thereby negatively affecting the growth potential through a loss of human capital. One extreme variant of is "downskilling", whereby highly qualified workers from the origin country leave to work in unskilled jobs in the destination country thereby losing their human capital altogether. In the European context, Hazans (2012) provides recent evidence from the Baltic countries, with a mix of brain drain and downskilling. At the same time, the author also points at the importance for origin countries of "brain gain" through return and circular migrants who acquired human capital abroad. Remittances also play an important role. at the microeconomic level for the families of migrants and at the macroeconomic level for the whole economy of the origin country. The role of remittances is particularly pronounced when the level of emigration is large and the income level of the origin country is significantly lower than in the destination country. Constant (2012) provides an up-to-date review on the role of remittances in the New Member States of the EU.

A common feature of numerous economic studies of migration is their limited attention to the topic of international portability of social benefits. This is slowly changing in light of ever-increasing migration flows. First, there is a broader recognition of portability of social benefits as a determining factor - and potential obstacle - in migration decisions. International migration almost inevitably implies a change from one social security system to another, with major consequences on an individual's pension, health insurance coverage, and well beyond. Any person's microeconomic incentives towards or against migration are thus heavily influenced by portability rules. Similarly, the incentive to claim any specific social benefit will depend on applicable portability rules regarding this benefit. Second, migration has multiple consequences for the social security systems of the origin 
and the destination countries and creates interdependencies between them. For example, it affects the contributor base and the risk pool of the two countries' social security schemes.

The present paper proposes a stimulating look at the role of portability of social benefits for migration. It draws on the literatures on migration and pensions as well as pensions and retirement to explore the role and impact of international coordination regarding social benefits. To clarify and stylize our arguments, we focus on the European context with its large migration flows and rather intense (and unique) international coordination framework.

The paper is structured as follows. Section 2 presents basic findings from the literature on the role of migration on pensions. As it turns out, the literature has a strong focus on early life mobility. Section 3 summarizes the key results of the literature on micro-based analysis of pensions and retirement in a national setting. Both individual-level results and aggregate results are discussed, with a focus on the decision to retire and the consequences thereof. Section 4, explores the interconnections of these two very important literatures. Using the European example and focusing on the decision to retire from the labor market, we discuss how financial incentives for individuals with a migration background differ from those of individuals with purely national careers. We also identify likely system-level effects. The final section summarizes our findings and outlines some promising avenues for future research at the nexus of these literatures.

\section{Migration and pensions}

As discussed by Jousten and Pestieau (2002), three broad types of mobility can be identified from an economic point of view: at the beginning of the working life, during the working life and at the end of the working life. The mobility at these different stages of life has different motivations, consequences at the individual level and also different policy implications for the countries involved.

With regards to early-life mobility, the focus of the economics literature has often been on highly stylized models trying to analyze the impact of mobility on the viability and macroeconomic 
outcomes of various choices with respect to pension systems. For example, Cremer and Pestieau (2003), Kolmar (2007) and Gouveia (2011) consider the case of two countries each having the same non-homogeneous population (in ability and income) and only differing in the chosen degree of redistribution built into the pension system. ${ }^{1}$ The economies are modeled as overlapping generation (OLG) growth models. Pension systems are essentially characterized by an exogenously fixed retirement age and the single redistribution parameter. The authors explore the conditions under which the option of early-life mobility leads to different effective migration patterns, influences the choice with regards to the degree of redistribution through the pension system, and affects system sustainability - both for sending and receiving countries. While their focus is on the case of the placeof-work country paying the benefits to the retirees, other scenarios could easily be integrated. Breyer and Kolmar (2002) explore conditions under which decentralized pension systems lead to efficient outcomes in countries that are linked by migration flows. Again retirement is considered to be occurring at a fixed age. They show that harmonization of systems between countries is often not a sufficient condition for efficiency.

As compared to early life mobility, the question of mid-career mobility is technically somewhat more intricate. While for early life mobility the decision affects people before they have accrued any pension rights, this no longer holds for mid-career mobility. The extra challenge at this stage of the working life is thus to understand whether and how the individual's mobility decision impacts these rights.

From a normative point of view, the key conceptual issue - that extends well beyond pensions to other social security benefits - is to understand how individuals and systems should be treated when there is mobility from one system to another. More specifically, should individuals and/or systems face the financial consequences of such individual-level mobility decisions? If they should bear these

\footnotetext{
${ }^{1}$ In the terminology of Cremer and Pestieau (1998) this is the so-called "Bismarckian factor", i.e., a factor summarizing the degree of redistribution across ability types between 1 (purely Bismarckian system - strictly contributions-linked pensions) and 0 (purely Beveridgean - purely uniform benefits).
} 
consequences - that can a priori be positive or negative - how should these be split between the individual and the system? The conceptual approach of Holzmann and Koettl (2011) is particularly useful in addressing this problem. They suggest an analytical framework to separate the risk-pooling, pre-funding and distributive elements of the various social insurance benefits. By explicitly separating these different aspects, these authors pave the way for a more detailed analysis of the topic - among others by linking it to other literatures.

For example, the impact of mid-career mobility on individual benefits is similar to the extensively studied issue of portability of private (or public) pensions across plans at the national level. ${ }^{2}$ The main difference between the national and the international context is not so much a question of type but more of degree - with often larger cross-country disparities in income as well as other socioeconomic parameters at the individual and the aggregate level. As a result of this similarity with the purely national context, and based on experience and analysis at that level, it is not uncommon to hear frequent references to a "dominance" of defined contribution (DC) over defined benefit (DB) pensions on mobility grounds. The logic is simple: portability and mobility are simplified as, a priori, the value of a DC scheme is easier to determine than the value of a DB scheme at any given point in time hence making the effects of a move easier to evaluate. Though the basic intuition behind this idea is compelling, Bodie, Marcus and Merton (1988) already warned that this supposed preference for DC over DB schemes should not be seen as innate to the DB or DC design itself, and actually needs to be traced to the specific accrual and indexation features of the various pension schemes both DB and DC.

From a positive point of view, two issues arise. First, how are individuals affected by mobility in terms of loss (or continuation) of coverage and/or the loss (or protection) of accrued rights in the real world? Second, how are system finances affected when individuals move from one system to

\footnotetext{
${ }^{2}$ We understand the concept of portability of pension rights at the national level in a broad sense as encompassing the ability of an individual that changes jobs to keep accrued to date pension rights, to preserve their value until retirement (or reaching a given age), and to have the right to transfer those rights from the former employer's pension scheme to the new employer's scheme.
} 
another? To our knowledge, very little - if any - systematic economic analysis has been done on these issues. In fact, the debate and the political decision-making in the field of international portability of social rights have, by and large, been dominated by social law and benefit practitioners. One major reason is no doubt the practical need for legal and administrative guidelines to be applied to individuals in situations of international mobility. For example, rules pertaining to coverage and eligibility, as well as with to the legal status of individual accrued rights need to be defined.

However, such an approach focused on (maintaining) individual rights may give rise to a whole set of economic incentive issues at the individual level, as well as non-trivial financial consequences at the system level. Thus, while there is need and substantial scope for promising positive economic analysis, two big obstacles hinder the development of such a literature. On the one hand, countries often differ greatly in their pension arrangements - particularly when considering supplementary pensions. ${ }^{3}$ On the other hand, and maybe partially because of this large heterogeneity in pension arrangements (both social security and supplementary), there is a severe issue of data availability that hinders the effective development of an empirical literature.

Last but not least, we turn to the third type of mobility: upon or after retirement. This kind of mobility raises an additional set of issues beyond those already discussed. In fact, such a situation of individual mobility essentially corresponds to a shift of purchasing power from the country of work to the new country of residence - particularly when focusing on pension payouts. For the origin country (the country of work), and leaving aside any possible income tax consequences, it reduces the disposable income in the economy and thus also the consumption tax base as the benefits are paid to (and largely spent by) an individual residing abroad. For the destination country, the picture is a different one as the new resident brings along a continuous stream of income from abroad. Hence, when focusing on pensions, there is a net gain in the disposable income, and thus in the consumption tax base for the destination country. This basic mechanism of a shift of purchasing power has been

\footnotetext{
${ }^{3}$ This limitation has been explicitly recognized in the recent White paper of the European Union on adequate, safe and sustainable pensions (European Commission 2012).
} 
the driving force behind some implicit or explicit policies trying to attract retirees such as, for example, recently in Portugal. ${ }^{4}$ We are however not aware of any systematic analysis of the effective macroeconomic benefits of such retiree-friendly policies for the destination country.

But beyond this macroeconomic level, such mobility upon retirement also has individual-level consequences going well beyond pensions; in fact, mobility may induce simultaneous - and sometimes more significant and conflicting - impacts at the level of other social (or private) programs or benefits than those at the pension level. For example, Werding and McLennan (2011) document and analyze the rules regarding health insurance eligibility and coverage across the world. In practice, mobility to a destination country with preferential taxation may simultaneously imply completely losing out on health insurance coverage or alternatively obtaining a worse insurance coverage than in the country of origin. Similar issues can arise with respect to long-term care insurance, as evidenced by the arguments in a recent judgment of the European Court of Justice. ${ }^{5}$

\section{Pensions and retirement}

Starting with the seminal work of Feldstein (1974), an important body of research has developed on the numerous interactions of pension systems and retirement behavior. Diamond and Mirrlees (1978) is an early contribution exploring the role of asymmetric information on pension systems and retirement. Kotlikoff (1979) provides empirical evidence on the link between pensions and retirement - while at the same time stressing the irrelevance of pensions for retirement in a world of perfect markets, actuarially fair pensions and certain lifetimes. Crawford and Lilien (1981) relax these assumptions and study the role of longevity risk, market imperfections and unfair pension pricing. Their results show that while pension systems are likely to affect the optimal choices of individuals, the sign of the induced change is uncertain given opposing income and substitution effects.

\footnotetext{
${ }^{4}$ See http://www.telegraph.co.uk/finance/personalfinance/expat-money/9474301/Portugalrelaxes-tax-rules-for-expats.html.

${ }^{5}$ See the recent judgment in the case of Van der Helder and Farrington vs. College voor zorgverzekeringen, ECJ 10/10/2013, C321-12.
} 
A complete review of the literature on pensions and retirement is well beyond the scope of the present section. Our focus is rather on highlighting two key research developments in the field of pensions and retirement that are of particular importance when considering the impact of migration on pensions and retirement.

A first relevant research domain relates to the study of how observed or assumed aggregate retirement patterns influence the generosity, adequacy and sustainability of national pension systems. A prominent application of this type of modelization is the work of the Aging Working Group in the European Union where activity rates and retirement patterns are projected according to exogenous pathways as indicated by national law - or as assumed to occur under a variety of reform scenarios. ${ }^{6}$ Such aggregate analyses have their merits as they indicate of how major macroeconomic parameters are linked and how they frame the outcomes of a pension system under different reform alternatives. However, these models also have their limits when it comes to understanding how aggregate assumptions on employment and retirement rates can in practice be implemented and decentralized in a world where behavior is dependent on the personal characteristics of the decisionmaker and thus endogenous. Such real-world decision-making will be influenced by financial and non-financial incentives that economic agents face, and this includes workers, employers and governments. The empirical analysis of the influence of individual level incentives on workers' retirement decisions is the second strand of literature that we focus on. Employers and the government may also face incentives to either release workers early into retirement or keep them working depending on incentive structures they face. For example, Hutchins (1999) frames early retirement as the result of the employer's process of profit-maximization. At the system level, decision-making may also be influenced as recently discussed in the context of Belgium by Koźluk et al. (2012). These authors identify that an absence of tax-benefit linkages in the Belgian retirement

\footnotetext{
${ }^{6}$ See, e.g., the Ageing Report 2012 (European Policy Committee and European Commission 2012).
} 
systems de facto eliminates incentives of plan administrators to contain pension spending in the face of ever increasing age-related spending requirements.

However, most empirical work has focused on the worker side. Gruber and Wise (2004) and Wise (2012) provide key contributions in this field for a dozen developed countries. These volumes contain individual country studies - providing a rich set of analysis of the interactions between the institutional architecture and individual behavior in a variety of social protection designs. Individual level incentives can take multiple forms. For example pensions can be adjusted in an actuarially neutral or non-neutral way when varying the retirement age. Other social security programs can play a role - such as unemployment or disability insurance. Non-monetary factors may also matter, such as social norms, higher levels of life satisfaction from either working or alternatively retirement such as summarized in the review of van Erp et al (2013).

Using microeconomic data at the individual level, the country studies in Gruber and Wise (2004) document three main findings. First, incentives towards early retirement are built into many Western European pension systems and these incentives to retire early are independent of the basic distributive characteristics of the systems. ${ }^{7}$ Second, each worker's personal characteristics are important in determining his effective retirement incentives and retirement behavior - rather than any type of mechanical indicators of typical workers or averages for entire birth cohorts. In the econometric modeling, each individual's decision to retire is based on the specific environment he faces. The various country studies documented a large degree of heterogeneity in incentives across the population - depending on the specific socio-economic characteristics faced by the individual. For example, beyond pure household characteristics, the exact career profiles and wage trajectories

\footnotetext{
${ }^{7}$ For example, the authors show that though Germany relied mostly on a Bismarckian pension system and the United Kingdom on a Beveridgean logic, incentives to retire early were rather comparable. Similarly, though the Netherlands has a major role for fully funded private pensions whereas Belgium, France and Italy are quasi-exclusively Pay-As-You-Go (PAYG) systems, they all share comparable incentives to retire early.
} 
over the life-cycle play a crucial role in determining future benefit entitlements and the associated adjustments for early or late retirement.

Third, average effective retirement ages are sometimes well below the earliest retirement age of the pension system of a country - usually due to the availability of some other social security benefits as a means of effective early retirement income. ${ }^{8}$ The list of relevant programs, as well as the age range during which people actually had an option to retire varies widely across countries - as most recently documented in Wise (2012). What is common across countries is the need to take a comprehensive look at all programs that are of relevance to potential retirees, as programs are interdependent. For example, tighter eligibility criteria affecting disability insurance will not necessarily lead to later effective retirement, but possibly simply to higher enrollment in another social insurance program such as unemployment insurance. This interdependence should not come as a surprise, as it is the intuitive result of rational individual decision-making in the face of a set of options. It is not void of policy relevance: the importance of looking at the social insurance system as a whole, rather than as an assembly of segmented programs to be analyzed and treated separately.

Two polar case studies are worth highlighting as they illustrate the range of situations. First, Coile and Gruber (2004) discuss the case of the US, with a rather simple environment where retirement and early retirement options are essentially limited to those that are open within the public Social Security system. People desiring to withdraw from the labor force are limited by the age range of early retirement options, while effective retirement incentives are determined by the actuarial adjustment factors built into the system. Second, Dellis et al. (2004) analyze the case of Belgium where retirement incentives are less standardized as the system architecture is significantly less uniform. In Belgium, three main pension regimes exist for contractual civil servants, for wage earners and for self-employed - listed in decreasing order of generosity. Both benefit eligibility and generosity vary significantly across schemes, with significant non-neutralities for mid-career movers

${ }^{8}$ See, for example, Table 2.1. of the OECD publication Pensions at a Glance (OECD 2011) for a recent survey of observed and statutory retirement ages. 
across schemes. ${ }^{9}$ Within the strict limits of each of these schemes, workers face different incentives to retire earlier than the regular retirement age of 65. Beyond the strict limits of the pension system, a series of alternative social insurance programs play an important role in determining incentives for early withdrawal from the labor force, such as formal early retirement programs organized outside of the pension scheme, unemployment insurance, sickness and disability insurance - with effective early retirement options available to individuals at ages as low as 50.

\section{Migration and benefit entitlements in Europe}

The preceding two sections have set the stage for discussing the link between migration and benefit entitlements. Each one of these literatures has its merits: the first in positioning the migrant and the national pension systems in their international context; the second, in expanding the scope beyond pensions in a strict sense and recognizing that retirement behavior is a decision rather than a government-imposed parameter. The basic recommendation in terms of a research agenda for the future is thus rather simple: stimulate research at the nexus between these two separate - and very active - literatures to push the research frontiers beyond their current limits. The ultimate aim should be to gain a better understanding of the link between migration, benefit entitlements and retirement both at the theoretical and the practical level.

The policy relevance of such an endeavor in the context of the European Union (EU) is selfevident. As a general principle, the freedom of movement rules for workers represent a backbone of the European integration - with the logic of economic gains from integration (and mobility). ${ }^{10}$ Similarly, the freedom of retirees to relocate upon (or after) retirement, though less developed than the freedom of workers, allows relocations of purchasing power across countries.

\footnotetext{
${ }^{9}$ The three systems are DB systems with largely different benefit formulas. As a result, nonneutralities appear that are akin to those discussed in section 2 .

${ }^{10}$ In what follows we mostly refer to intra-European mobility by citizens of the countries that are part of these multilateral agreements. Outward mobility to non-member countries is sometimes regulated on a bilateral basis. See Avato et al (2009) for a broader survey of social protection for international migrants.
} 
In practical terms, we can observe ever-increasing levels of cross-country mobility. First, more and more EU citizens have partial work careers in several countries thus increasing the importance of understanding the individual-level consequences of the legal and administrative arrangements for mobility. As a matter of example, the benefit level that an individual will receive during retirement may crucially depend on whether he or she is considered to have had a full career - hence the importance of knowing how career fragments in different countries are treated upon retirement. Second, increased mobility in the EU is not without consequences for pension and other social protection schemes. For example, mobility can lead to linkages and externalities between systems as discussed in section 2. Also, mobility can be non-neutral for the budget of any given country when an individual's mid- or end-of-career mobility is not accompanied by the appropriate budgetary transfers.

The present section can be seen as a first attempt at identifying some key dimensions of the current EU policy environment with respect to cross-border migration that have - or at least have the potential to have - substantial economic effects.

The core of the European legal and administrative framework applicable to the portability of social security rights is set in regulations EC $883 / 2004$ and EC 987/2009 on the coordination of social security systems. They apply to all traditional branches of social security (both public and private), namely sickness, maternity, accidents at work, occupational diseases, unemployment benefits, preretirement benefits, retirement benefits, survivor benefits and death grants. Effectively, these regulations recognize minimum standards in terms of each individual's rights in situations of mobility - granting member states the right to allow a more favorable treatment than the one specified in these regulations either by national law or bilateral agreement.

Two important characteristics of these regulations are worth emphasizing at the outset. On the one hand, these regulations merely coordinate independent (national) systems - they don't either harmonize or integrate these systems. This means that the various national systems remain 
operational, with their own national characteristics in terms of generosity, financing, redistribution, etc.

On the other hand, the regulations grant people a right to invoke these coordination mechanisms - not an obligation to do so. While the distinction between both may look tenuous at first sight, it may be less so both in theory and in some relevant practical situations. At the theoretical level, numerous social security benefits are not mechanically awarded but rather require an explicit application or claim to be activated. ${ }^{11}$ On the practical side, anecdotal evidence from the field suggests that some retirees strategically abstain from applying for pension benefits in their country of residence so as to maintain long-term care coverage provided by their former country of work. Such behavior may be perfectly rational, if the country of residence does not provide extensive longterm care benefits while the former country of work does.

These regulations represent a rather uncommon approach at the international level for several reasons. First, in the field of portability of social rights, the most common approach to dealing with issues of international mobility is to either rely on a set of bilateral social security treaties or, absent thereof, to use unilateral default rules - contrary to these EU regulations that are decidedly multilateral tools with an extremely broad scope. Though other examples of multilateral agreements for policy coordination exist in the field of social protection ${ }^{12}$, none is as extensive.

Second, when comparing to other areas of coordination, such as on taxes, bilateral treaties are still the predominant tool for coordinating national tax systems to prevent situations of double taxation (and non-taxation). Even in the European context, tax coordination mostly a bilateral matter - with sometimes substantial differences between the various bilateral double tax treaties.

\footnotetext{
${ }^{11}$ Another reason for an imperfect link between migration and benefit entitlements is provided by MacAuslin and Sabates-Wheeler (2011), who insist that beyond the above issue of take-up, there may also be separate issues of selective eligibility or benefit provision applying to immigrants.

${ }^{12}$ See for example Werding and McLennan (2011).
} 
The EU regulations have important consequences both at the individual and the system-level which we will discuss in turns. Given our positioning in the retirement context we mostly focus our discussion on unemployment, pre-retirement, retirement, sickness and disability programs - but will also cover health benefits particularly with respect to their impact on system finances.

It is worth noting that these regulations do not apply to supplementary pensions, nor do they apply to civil servant pensions - hence leaving these two sectors at present without a harmonized and/or unified portability regime. The White Paper (European Commission 2012) explicitly recognized this obstacle to mobility caused by supplementary pensions and stressed the need for an environment in which they become safer and truly compatible with mobility. As a result, this situation is likely to change in the very near future: most recently, on 20/06/2013 a major breakthrough was achieved regarding an improved portability of supplementary pensions. The European Council for Employment, Social Policy, Health and Consumer Affairs reached an agreement on a general approach to the European Commission's proposal for a directive on improving the portability of such pension rights. While details are still uncertain, the portability provisions will be well short of those under regulations EC 883/2004 and EC 987/2009. ${ }^{13}$

\section{Individual level discussion}

At the individual level, the EU regulations regarding social insurance are based on three main principles: 1 . Any person is only subject to the legislation of a single member state (double coverage in two separate member states is not allowed); 2. Equal treatment of all EU citizens (no discrimination); and 3. Aggregation of periods across member countries. While the first two guiding principles apply immediately to all branches of social security, the third one has a differential impact for the different benefit types.

From an economic point of view, the various types of benefits covered by the regulation can be classified into three broad categories. The first category of benefits involves what we would qualify

\footnotetext{
${ }^{13}$ See Council of the European Union (2013).
} 
as "immediate risks" - where the coverage offered by a country is solely based on the current insurance status of the individual at the moment when the negative event occurs. Benefits included in this category are health insurance, unemployment benefits as well as some limited number of EU countries' disability programs that are explicitly mentioned in Appendix 6 of regulation EC 883/2004. ${ }^{14}$ For those programs, in line with the first principle, one country is competent - usually the place of residence or the main place of work. It is this country's legislation that determines the rules of enrollment in the relevant social security scheme. In line with the second principle, all people immigrants or not - are treated identically under the competent national scheme. In line with the third rule, and where useful, periods of affiliation under other member country schemes are aggregated to determine benefit eligibility in the competent country - a process known as totalization. ${ }^{15}$

The second category of benefits could be qualified as "life-cycle risks" - where countries pay benefits in proportion to the share of the career the worker has worked under their social security legislation (pro-rated benefits). The most common examples are retirement benefits as well as disability benefits for all other cases than those previously mentioned. The three principles again apply, meaning that only one country is responsible for each share of the worker's career. To prevent individuals from losing out over purely national careers, an aggregation mechanism applies upon benefit claiming including not only totalization, but also double calculation of benefits in each country - once on a stand-alone basis, and once based on a pro-rated formula integrating years of service abroad. Finally, the country of residence has an extra obligation under these rules: make a gap-filling payment, if ever the sum of the worker's various entitlements is lower than the minimum

\footnotetext{
${ }^{14}$ The case of disability programs is particularly complicated. While several EU countries have an "immediate risk" philosophy in their national disability programs - they have opted not to include their system in Appendix 6. Therefore, the immediate-risk philosophy is not applicable for cases of international mobility - while it would be applicable for cases of national mobility.

${ }^{15}$ One example may help illustrate the process of totalization. If a country imposes a minimum period of contributions of 2 years to be eligible for unemployment insurance benefits, and the worker can prove 2 years of contributions in another member state, then the process of totalization allows him to "use" these foreign years towards the fulfillment of the minimum contribution requirement.
} 
social insurance benefit to which he would have been entitled, had his career been a purely national one.

The third category is made up of a single category of benefits: formal pre-retirement schemes. Under the EU regulations, formal pre-retirement programs are explicitly included in the text but no totalization is allowed - de facto rendering these programs purely national matters. ${ }^{16}$ These formal early retirement schemes have to be distinguished from all early retirement arrangements that are organized either formally or informally as sub-divisions of other social protection schemes. For example, Luxembourg has a formal pre-retirement program that qualifies as such as it is set up as a separate and well-defined program. Opposite examples are the Dutch early retirees benefiting from disability insurance benefits, or their French and Belgian counterparts that are retired under the cupola of unemployment insurance benefits. The latter would be classified as belonging to the second or the first category of benefits - and not to the category of pre-retirement programs!

The substantially different treatment of the various social security schemes is not surprising as such. Indeed, it can be directly traced back to the fact that the EU regulations do not attempt to harmonize systems - they merely attempt to coordinate systems, insofar as individual mobility requires such coordination. Seen from another point of view, this means that all member countries keep their individual social security schemes in all traditional branches of social security with all their differences in entitlement ages, entitlement conditions, entitlement levels, benefit adjustments, dependent benefits, intra- and intergenerational degree of redistribution, etc.

The differential treatment is however problematic when positioned in a context where the borders between various branches of social security become blurry - for example when considering (early) retirement. As discussed in section 3, any program that provides an income stream (temporary or open-ended) to an early retiree or retiree is of relevance in understanding and

\footnotetext{
${ }^{16}$ Technically, the absence of totalization is justified by the fact that such systems are not available everywhere.
} 
analyzing the retirement decision. This implies that the very different treatment of the various benefits under the EU regulations will almost inevitably have an impact on retirement incentives, and thus also in effective retirement behavior. While the non-neutrality of these rules is relatively easy to conceptualize, the sign of the effect in terms of retirement probabilities will heavily depend on the country specifics, the social security program involved, as well as on the individual's specific mobility pattern. Several examples may again help illustrate this rather general point.

A first compelling example relates to early retirement. If programs are formally declared as such, early retirees do not have a right towards totalization. Now consider a case of a country imposing a 35 year work career length requirement for access to the formal early-retirement program. In such a case, a migrant worker with a 35 year total career of which he spent half in his country of origin would not qualify for such pre-retirement benefits - whereas a worker with a purely national career would qualify. Now consider the same early retirement program, this time organized under cupola of unemployment insurance rather than formal early-retirement. Both workers - migrant and national would be treated equally.

A second example relates to disability insurance in the (most frequent) case of a life-cycle philosophy of benefits. Consider an individual applying for disability insurance in his current country of work - be it for reasons of physical impairment or as a matter of early retirement. Given the lifecycle conception of benefits, it means that the individual' eligibility is evaluated and benefits are awarded based on the rules in his current country of work for the part of the career that he worked in this country. If the worker completed his entire professional career in this country - a hypothesis usually assumed in early retirement studies at the national level -financial incentives towards early retirement would be easy to determine as benefit entitlements are entirely based on the country's legislation. If, however, the worker spent part of his career abroad, the situation would be very different: benefit eligibility and generosity for the foreign part of the career would be based on that country's rules and regulations. Depending on the systems, one country may consider a person 
disabled while the other may not, or the countries may differ in the assessment of the degree of disability. Similarly, the benefit levels and rules may vary substantially between countries. ${ }^{17}$ As a result, incentives faced by older workers with a migrant past are most likely very different from those of non-migrants.

A third case relates to regular social security retirement benefits. Consider a worker who applies for retirement benefits in his current country of employment at the normal retirement age - which we assume to be fixed at 62 . If this worker has a purely national career, the calculation of the benefit entitlement and the ensuing economic incentives are easily determined. The case of a worker with a migrant past, and a partial career abroad is less obvious. Though falling under the category of "life cycle risks", severe benefit consequences and incentive-for-retirement issues may arise. On the one hand, as compared to purely national workers, retirement benefit levels may vary substantially hence leading to different incentives to retire. Similarly, eligibility ages and actuarial adjustments for early or late retirement may also vary between countries -leading to sometimes rather large differences in retirement incentives. The issue is most severe if in the country of origin the normal (or even the minimum) entitlement age is higher. In this case, the worker may have substantially lower incomes in the interim period until he finally fulfills the age conditions in both countries - further reinforcing the differences in incentives. On the other hand, social insurance benefits interact with social assistance benefits - again affecting incentives. For example, this could be the case in the above-mentioned interim period - where the difference in eligibility age may lead to eligibility for social assistance pensions.

In sum, our conceptual discussion as well as the several stylized examples illustrate that internationally mobile workers are likely to face substantially different incentive structures from those encountered by purely national workers. While mobile careers are playing an ever-increasing

${ }^{17}$ The EU coordination arrangements do not include coordinated assessment criteria and procedures for disability insurance -countries thus keep full control over system operations beyond the 3 main principles. 
role in today's labor market, very little empirical evidence is currently available on such cross-border careers. For example, there is no systematic administrative communication among countries regarding the various national career segments of any individual during his working life... It is merely upon claiming a life-cycle benefit that some of these pieces of information are exchanged.

\section{System level discussion}

Beyond the individual decision-making process, there are also the impacts of the regulations on system functioning, as well as on international burden-sharing arrangements with respect to budgetary costs. Indeed, and insofar as the mobility across countries is not associated with the adequate transfers reflecting the full insurance, savings and redistributive components of Holzmann and Koettl (2011), any transition between systems will have a non-neutral effect in terms of financial burdens for the source and origin countries. ${ }^{18}$ In reality, no such stylized transfers exist - thus leading to potentially large non-neutralities for system finances.

On the one hand, life-cycle risks are least affected by this problem. The reason is simple. Each country is by and large responsible for financing and setting the benefit rules regarding the part of the career during which the individual was affiliated with its system. This means that the various countries' rules are rather well delimitated - leaving aside exceptions such as the special role of the residence country for pensions as well as the interaction between social insurance and social assistance benefits.

Health insurance, on the other hand, is likely one of the most affected programs thus also generating the most compelling cases of the importance of explicit and implicit financial transfers. First, for numerous cases of mobility no financial compensation is due between systems. This is notably the case of early-life or mid-career mobility. While it is impossible to affirm whether the

\footnotetext{
${ }^{18}$ Notice that these compensating transfers can be introduced both in insurance-based and in general revenue financed systems - as the key determinant for the transfer is the expected cost, not the revenue structure.
} 
source or the benefit countries lose or win, it is clear that any such transitions from one country to another one will be non-neutral in the generic case. ${ }^{19}$

Second, other cases of mobility do involve a financial compensation between countries for the health coverage - and some of these also involve the mobility of pensioners. For example, this applies to the situation of an individual who moves at the end of the working life to a different country than his previous country/countries of work. While the individual will be subjected to the new residence country's benefit rules, the financial cost linked to his coverage will be borne by the country where he worked and from which he gets a pension. In general, a financial compensation is thus due by the pension-paying country to the new residence country to compensate the latter for the extra costs of the new resident. If he worked in multiple other countries then it is the country with the longest period of affiliation or - if this rule doesn't provide a clear answer - the last country of work that has to pay. Under the regulations, the resident country can claim either realized costs or average costs associated with a comparable national retiree. ${ }^{20}$ One corollary from this dichotomy is that situations arise where systems have to bear costs that are generated in a sister scheme (abroad), without the paying country having any immediate control of the costs incurred.

The discussion on non-neutralities of mobility with respect to system finances should be particularly important for countries with either large emigrant or immigrant populations. But beyond the sheer importance of migration, the precise composition of flows also matters for system finances. For example, while one could argue that such non-neutralities should not matter much in a world of symmetric bi-directional migration flows between equally developed countries having made comparable choices with respect to system generosity, the same does not hold in the presence of strong migration corridors from typical emigrant countries to typical immigrant countries, or when

\footnotetext{
${ }^{19}$ The country-specific impact depends on the relevant risk pools' characteristics.

${ }^{20}$ Notice that if the worker would have any pension entitlements in his retirement residence country, it would be the latter that would have to bear the full financial burden - thus eliminating any right to financial transfers.
} 
countries or their system parameters differ as illustrated in section 2. In both origin and receiving countries, the issue should be of prime policy relevance.

\section{Concluding thoughts}

In light of increasing migration flows, a better understanding of the impact of mobility on individual behavior, as well as on social security systems, takes on prime policy relevance. To discuss our ideas, we position the paper in the European context - as it is here that the regulatory environment regarding international coordination of social security benefits is most developed. The paper starts by proposing a stimulating look at the literatures on mobility-induced effects on pensions and on the effects of pension systems on early retirement. Our discussion highlights the important policy lessons of the existing literatures. We argue that there is substantial room for improvement and that and a cross-fertilization of these domains looks warranted. This observation is particularly true given the large shares of populations with a migrant background in Europe and beyond.

Several key observations emerge from the European context. First, while the regulations in place help coordinate programs, they do not set out a harmonized or unified social protection system thus maintaining possible incentives for migration between countries.

Second, we find that the European coordination regime is non-neutral, both at the individual and the system level. At the individual level, it implies that a simple look at the worker's national professional trajectory is insufficient - and likely even misleading. The reason is that many social programs have an explicit intertemporal dimension: people will still be exposed to rules and benefits from their former country/countries of work. This has immediate policy relevance in the field of retirement - but also well beyond. As illustrated by the early retirement literature, retirement is endogenous and a dynamic process - not a simple policy parameter. As such, individuals decide on (early) retirement based on their personal context - which also includes the migrant past. Ignoring 
this dimension thus risks leading to erroneous and misguided social and labor market policies - with the degree of error depending on the precise interactions of the various countries' schemes. Clearly, the basic argument also holds true for other country contexts - with or without formal coordination regimes in place.

At the system level, the coordination mechanism is also non-neutral. While the benefits and financial charges for retirement and disability essentially follow a life-cycle logic of pro-rating among countries based on the share of the career covered by the system, the situation is very different for programs such as health insurance (or unemployment insurance) where substantial non-neutralities appear. For example, mid-career migration leads to a switchover from one system to the other at the moment of migration - without any financial compensation between the countries. Other budgetary issues arise at the system level for end-of-the-working-life mobility.

We thus recommend that substantial research efforts be directed at evaluating the role of foreign careers on the behavior of individuals with a migrant past. Such an effort would almost inevitably involve a first phase of data collection. In fact, to our knowledge, no country systematically tracks information on foreign careers during an individual's working life. At present, a partial exchange of information usually only occurs upon the introduction of a benefit claim by an individual. Such data availability during the working life is however crucial to understand the incentives that people face - for example with respect to early retirement decisions. In a second phase, substantial efforts should be directed at improving the understanding of the true incentive structure faced by individuals with a migration background - for example with respect to early retirement decisions. Also, in a period of budgetary pressures and in face of an aging population, it is useful for governments to get a better idea of the financial implications of the prevailing mobility to gauge the budgetary impact, but also to possibly frame reforms for the future.

\section{Bibliography}


Avato, J., J. Koettl and R. Sabates-Wheeler (2009), “Definitions, Good Practices, and Global Estimates on the Status of Social Protection for International Migrants", World Bank Social Protection Discussion Paper 0909.

Bodie, Z., A. Marcus and R. Merton (1988), “Defined Benefit versus Defined Contribution Pension Plans: What are the Real Trade-offs?", in Zvi Bodie, John Shoven, and David Wise, eds., Pensions in the U.S. Economy, University of Chicago Press, Chicago, p. $139-162$.

Borjas, G. (1995), “The Economic Benefits from Immigration”, Journal of Economic Perspectives 9, 3-22.

Breyer, F. and M. Kolmar (2002), “Are national pension systems efficient if labor is (im)perfectly mobile?", Journal of Public Economics 83, 347-374.

Coile, C. and J. Gruber (2004), "The Effect of Social Security on Retirement in the United States", in Jonathan Gruber and David Wise, eds., Social Security Programs and Retirement around the World: Micro-Estimation, NBER and University of Chicago Press, Chicago, $691-730$.

Constant, A. (2012), "Sizing It Up: Labor Migration Lessons of the EU Enlargement to 27", in Gortázar, C., Parra, C., Segaert, B. and Timmerman, C., eds., European Migration and Asylum Policies: Coherence or Contradiction, Bruylant, Brussels, 49-77.

Council of the European Union (2013), "Amended proposal for a Directive of the European Parliament and of the Council on minimum requirements for enhancing worker mobility by improving the acquisition and preservation of supplementary pension rights - General approach", Council General Secretariat Report to the Delegations, Document Number 11459/13, Brussels.

Crawford, V. and D. Lilien (1981), "Social Security and the Retirement Decision", The Quarterly Journal of Economics 96(3) 505-529. 
De Giorgi, G. and Pellizzari, M. (2010), "Welfare migration in Europe”, Labour Economics 16, 353363.

Cremer, H. and P. Pestieau (2003), "Social Insurance Competition between Bismarck and Beveridge", Journal of Urban Economics 54, 181-96.

Dellis, A. , R. Desmet, A. Jousten and S. Perelman (2004), “Micro-Modeling of Retirement in Belgium", in Gruber, Jonathan and David Wise, eds., Social Security Programs and Retirement around the World: Micro-Estimation, NBER and University of Chicago Press, Chicago, 41-98.

Diamond, P. and J. Mirrlees (1978), "A model of social insurance with variable retirement", Journal of Public Economics 10(3), 295-336.Dustmann, C., Frattini, T., and Halls, C. (2010), “Assessing the Fiscal Costs and Benefits of A8 Migration to the UK", Fiscal Studies, 31(1), 1-41.

Economic Policy Committee and European Commission (2012), "The 2012 Ageing Report: Economic and budgetary projections for the EU27 Member States (2010-2060)", European Economy $2 / 2012$.

van Erp, F., Vermeer, N. and van Vuuren, D. (2013), Non-financial determinants of retirement, NETSPAR Panel Paper 34, Netspar, Tilburg.

European Commission (2012), "White Paper: An Agenda for Adequate, Safe and Sustainable Pensions", COM(2012) 55 final, European Commission, Brussels.

Feldstein, M. (1974), "Social Security, Induced Retirement, and Aggregate Capital Accumulation", Journal of Political Economy 82(5), 905-926.

Gouveia, A. (2011), "The political economy of pension systems under free labor mobility", mimeo. 
Gruber, J. and D. Wise, eds. (1999), Social Security Programs and Retirement around the World, NBER and University of Chicago Press, Chicago.

Gruber, J. and D. Wise, eds. (2004), Social Security Programs and Retirement around the World: Micro-Estimation, NBER and University of Chicago Press, Chicago.

Hazans, M. (2012), "Selectivity of migrants from Baltic countries before and after enlargement and responses to the crisis", in Galgóczi B., Leschke, J. and Watt, A., eds., EU Labour Migration in Troubled Times: Skills Mismatch, Return and Policy Responses. Ashgate, Aldershot, 169-207.

Holzmann, R. and J. Koettl (2011), "Portability of Pension, Health and other Social Benefits: Facts, Concepts, Issues", World Bank Social Protection Discussion Paper 1110.

Hutchens, R. (1999), "Social Security Benefits and Employer Behavior: Evaluating Social Security Early Retirement Benefits as a Form of Unemployment Insurance", International Economic Review 40(3), 659-678.

Kahanec, M. (2013), "Labor Mobility in an Enlarged European Union", in A. Constant and K. Zimmermann, eds., International Handbook on the Economics of Migration, Edward Elgar, Cheltenham, UK, and Northampton, USA, 137-152.

Kolmar, M. (2007), "Beveridge versus Bismarck public-pension systems in integrated markets", Regional Science and Urban Economics 37, 649-669.

Kotlikoff, L. (1979), "Testing the theory of social security and life-cycle accumulation", American Economic Review 69, 396-410.

Koźluk, T., A. Jousten and J. Høj (2012), "Bringing Belgian Public Finances to a Sustainable Path", OECD Economics Department Working Papers, No. 954, OECD Publishing. 
Jousten A. and P. Pestieau (2002), "Labor-mobility, Redistribution and Pension Reform in the European Union", in M. Feldstein and H. Siebert, eds., "Social Security Pension Reform in Europe", University of Chicago Press and NBER, Chicago, 85-108.

MacAuslan, I. and R. Sabates-Wheeler (2011), "Structures of Access to Social Protection for Migrants", in R. Sabates-Wheeler and R. Feldman, eds., Migration and Social Protection: Claiming Social Rights Beyond Borders, Palgrave Macmillan, Basingstoke, 61-90.

OECD (2011), Pensions at a Glance 2011: Retirement-Income Systems in OECD and G20 Countries http://www.oecd.org/els/social/pensions/PAG.

OECD (2012), "International Migration Outlook, 2012", OECD Publishing, Paris.

Werding, M. and S. McLennan (2011), "International Portability of Health-Cost Coverage: Concepts and Experience", World Bank Social Protection Discussion Paper 1115.

Wise, D. , ed. (2002), Social Security Programs and Retirement around the World: Historical Trends in Mortality and Health, Employment, and Disability Insurance Participation and Reforms, University of Chicago Press and NBER, Chicago.

\section{Funding}

The paper was prepared for the CESifo conference "Portability of Social Benefits: The Economics of a Critical Topic in Globalization". Financial support for this research by CESifo and the SBO-project FLEMOSI (funded by IWT Flanders) is gratefully acknowledged.

\section{Acknowledgements}

The author wishes to thank Arjeta Aliaj and Maria Polipciuc for research assistance, the conference participants for helpful discussions and comments, and the editor and 2 anonymous reviewers for their comments and guidance. Special thanks go to the management team of the 
Inspection générale de la sécurité sociale (IGSS) and the Caisse Nationale d'Assurance Pension (CNAP) of Luxembourg for extremely stimulating discussions and insights. All remaining errors are entirely my own. Contact address: Alain Jousten, Université de Liège, Boulevard du Rectorat 7, B31, 4000 Liège, Belgium. ajousten@ulg.ac.be. 